\title{
Fatigue Crack Growth Behaviour of High Strength Ferritic Steels in High Pressure Hydrogen
}

\author{
Ashok Saxena ${ }^{1,{ }^{*}}$ and Kevin Nibur ${ }^{2}$ \\ ${ }^{1}$ Department of Mechanical Engineering, University of Arkansas, Fayetteville, AR, 72701, USA \\ ${ }^{2}$ Hy Performance Materials Testing, LLC, Bend, OR 97701, USA
}

\begin{abstract}
The design of safe and low-cost, high-pressure hydrogen storage systems are a critical need for harnessing clean power but must consider the propensity of hydrogen to accelerate fatigue crack growth rates in the construction materials. Design of safe pressure vessels needs robust models for predicting crack growth rates and how they are affected by variables such as loading frequency, load ratios, hydrogen pressure, gaseous impurities, temperature, and material variability. In this study, fatigue crack growth rates were measured in the liner material in $10 \mathrm{MPa}$ gaseous hydrogen at various load ratios, $\mathrm{R}$, in the range $-1 \leq \mathrm{R} \leq$ 0.2 . The effects of varying loading frequency were investigated, and the results were pooled with those from literature for similar alloys tested in $103 \mathrm{MPa}$ gaseous hydrogen pressure. The differences in crack growth rates between $\mathrm{H}_{2}$ pressures of 10 to $103 \mathrm{MPa}$ as well as the effects of frequency on the environment assisted crack growth rates were assessed. Loading frequency effects tend to saturate at frequencies of $1 \mathrm{~Hz}$ and less. $\mathrm{H}_{2}$ pressure effects appear to saturate at pressures of $45 \mathrm{MPa}$, while load ratio effects are not significant for $-1 \leq R \leq 0.2$ but become important for $\mathrm{R} \geq 0.2$.
\end{abstract}

\section{INTRODUCTION}

Safe and low-cost, high-pressure hydrogen storage systems are a critical need for refueling stations for fuelcell powered vehicles, for back-up power in residential and office buildings, and for fork-lifts in warehouses. Also, excess energy during high generation periods from renewable sources such as sun and wind can be stored in the form of compressed hydrogen that can be made available to power fuel cells during the low generation periods. $\mathrm{H}_{2}$ powered vehicles can reduce harmful pollutants in large metropolitan areas.

Type I, steel pressure vessels that have been in use in the industry for decades to store hydrogen on ground are constructed from seamless high strength low alloy steels, but are restricted to maximum pressures of 450 bar. This is due to hardenability considerations that limit the maximum permissible wall thickness of the vessel. For onboard vessels, their weight also becomes a limiting factor. Therefore, the challenge is to continue to use steel tanks for storing hydrogen that have been time-tested, but limit the maximum stresses in the interior of the vessel via good design to levels that have been successfully used in the past.

Calculations show that the maximum operating pressure of commercially available steel pressure vessels can be approximately doubled by incorporating a hoop wrap using high strength wires with tensile strength of 2 to $4 \mathrm{GPa}[1,2]$. The wires are held together by epoxy that otherwise does not have a strucrural role. These designs also include subjecting the vessels to hydro-pressures that are about twice the maximum design pressure during manufacturing to produce plastic strains in the liner while maintaining elastic behavior in the high strength steel wire wrap $[1,2]$. This process is known as autofrettage and the pressure used is called the autofrettage pressure. Upon removal of the autofrettage pressure, compressive stresses are locked into the wall of the steel liner. This, along with effective transfer of stresses from the steel liner on to the wire wrap, reduces the maximum stress in the liner to safe levels at which these vessels have decades of service history with an excellent safety record.

The American Society for Mechanical Engineers (ASME) has developed codes $[3,4]$ for designing pressure vessels for storing hydrogen but these codes are conservative because of gaps in our ability to confidently model the degradation kinetics of hydrogen embrittlement in these steels. There has been progress in our understanding of mechanisms of hydrogen embrittlement in the crack tip process zone [5] but not sufficient to allow development of robust models for predicting crack growth rates and how they are affected by variables such as loading frequency, load ratios, hydrogen pressure, gaseous impurities, temperature, and material variability. This need has been partially met by empirical studies conducted by Sandia National Laboratory and by Japanese and European research programs[6-8].

\footnotetext{
* Corresponding author: asaxena@uark.edu
} 
However, many more such studies must be conducted to meet the overall need of the designers of these vessels. For example, the acceleration of fatigue crack growth rates have been quantified for tension only loading conditions, but autofrettaged pressure vessels experience compression to tension load cycles during service [9].

\section{MATERIALS AND EXPERIMENTAL PROCEDURE}

Metal liners with outside diameter of $406 \mathrm{~mm}$ and a nominal wall thickness of $31.75 \mathrm{~mm}$ that were made from SA 372 (or A372) Grade J, Class 70 steel were procured for testing. The test specimens for generating fatigue crack growth rate data were extracted from one of these liners. The material chemistry and all mechanical properties met the standard requirements for this grade of material. The yield strength was $770.75 \mathrm{MPa}$, the UTS was $884.5 \mathrm{MPa}$ and percent elongation was $21.0 \%$. The microstructure consisted of the typical tempered martensite resulting from an oil quenched tempered low alloy, medium carbon steel.

Single edge crack tension, SEC(T) specimens, Fig. 1 , were machined from curved panels removed from the liner such that the crack orientation was circumferential radial (C-R). This orientation matches with the potential crack growth direction, axial-radial, in the pressure vessel. The specimens and their sizes were especially designed to test material that was directly taken from the liner and were capable of being tested under tension-compression loading. For more details on the specimen and its design, refer to reference [10]. The radial direction was along the crack plane and the loading direction was circumferential. A few $50.8 \mathrm{~mm} \mathrm{C}(\mathrm{T})$ specimens were also machined. All SEC(T) specimens were labelled WT-xx and the C(T) specimens were labelled WT-C(T)-xx.

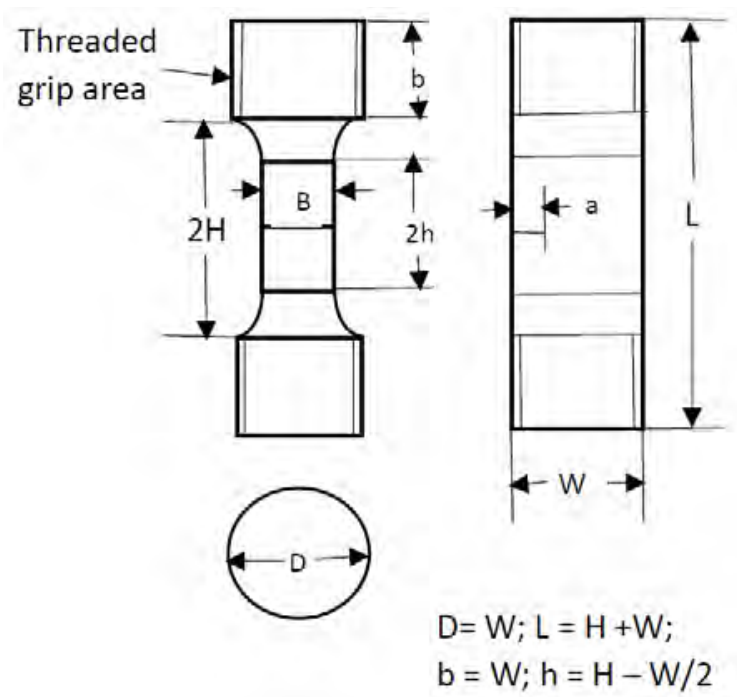

Fig. 1- Schematic of the SEC(T) specimens used for crack growth testing [10]

\section{RESULTS AND DISCUSSION}

In this section, the experimental results from this study and those from previously published studies are used to explore the kinetics of environment assisted cracking in A372 Grade J, Class 70 tempered martensitic steels for use in hydrogen storage applications. Figure 2 shows the effects of $10 \mathrm{MPa}, \mathrm{H}_{2}$ on the FCGR behavior of our test material at a load ratio of 0.2 compared to the same behavior in air and in helium $(\mathrm{He})$ environment. The results show that the crack growth rates are higher in air than in $\mathrm{He}$ and substantially higher in $\mathrm{H}_{2}$ at $10 \mathrm{MPa}$. These differences underscore the importance of susceptibility of this material to environment assisted cracking and the need to fully understand it. It is also important to systematically explore the effects of variables such as load ratio, $\mathrm{R}$, loading frequency, $v$, and hydrogen pressure on the FCGR behavior.

\subsection{Effects of Load Ratio on FCGR Behavior}

Fatigue crack growth rate tests on SEC(T) specimens were conducted under negative load ratios of 1.0 and -0.5 as well as positive load ratios of 0.1 and 0.2 . Positive load ratio data from these tests were compared with data from prior studies conducted by Sandia $[11,12]$ as shown in Fig. 3. The ASME trend line [3] for FCGR behavior in air is also provided for reference. Fatigue crack growth rate data obtained on SEC(T) specimens from this study and Sandia's data obtained on C(T) specimens appear to be identical at load ratios of 0.1 and a $\mathrm{H}_{2}$ pressure of $10 \mathrm{MPa}$. At $\mathrm{R}=0.2$ our data was at a pressure of $10 \mathrm{MPa}$ while the Sandia data was at $103 \mathrm{MPa}$; the FCGR behavior at the higher pressure does show a distinct tendency for higher crack growth rates. The crack growth rates at $\mathrm{R}=0.5$ are higher than the crack growth rates at $\mathrm{R}=0.1$ and 0.2 even after reconciling the differences in pressure.

Figure 4 shows a comparison between FCGR behavior at negative load ratios of -0.5 and -1.0 , and the positive load ratios of $\mathrm{R}=0.1$ and 0.2 . All data in this figure are from the current study and have been generated at a $\mathrm{H}_{2}$ pressure of $10 \mathrm{MPa}$. The data show that there is no systematic difference between the FCGR behavior between $\mathrm{R}$ values of -0.5 and -1.0 . This is entirely expected because negative loads do not contribute to the value of $\Delta K$ and if there are any plasticity induced crack closure effects that influence the value of the effective $\Delta \mathrm{K}$, they should have saturated for $\mathrm{R}=-0.5$. We note that the $\mathrm{R}=0.1$ data also blends with the trends for $\mathrm{R}=-0.5$ and -1.0 data. One of the tests at $\mathrm{R}=0.2$ yielded crack growth rates that are very comparable to the rates for $\mathrm{R}=$ $-1.0,-0.5$, and 0.1 while the other showed a somewhat higher rate. This indicates that at $\mathrm{R}=0.2$, the FCGR behavior of A372 Grade J Class 70 steels begins to 


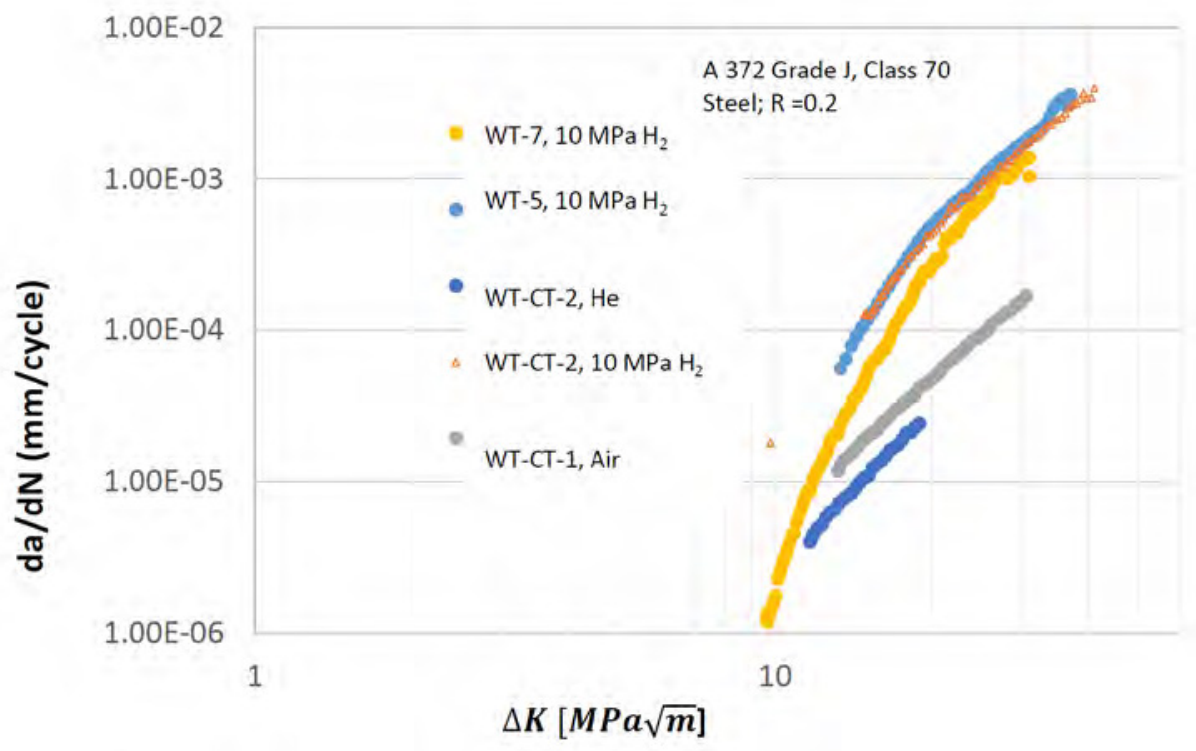

Fig. 2- FCGR behavior of A 372 Grade J, Class 70 steels in $\mathrm{He}$, air, and $\mathrm{H}_{2}$ at a load ratio, $\mathrm{R}=0.2$.

become sensitive to $\mathrm{R}$ in $\mathrm{H}_{2}$ environment. For $\mathrm{R}<0.2$, and continuing into negative $\mathrm{R}$ values, the FCGR behavior is not sensitive to $\mathrm{R}$ even in $\mathrm{H}_{2}$ environment. However, in comparison with the crack growth rates in air, the rates in $\mathrm{H}_{2}$ are consistently higher. For $\Delta \mathrm{K}>20 \mathrm{MPa} \sqrt{m}$, the differences between air and $\mathrm{H}_{2}$ are an order of magnitude or more but for $\Delta \mathrm{K}<10 \mathrm{MPa} \sqrt{m}$, the differences seem smaller.

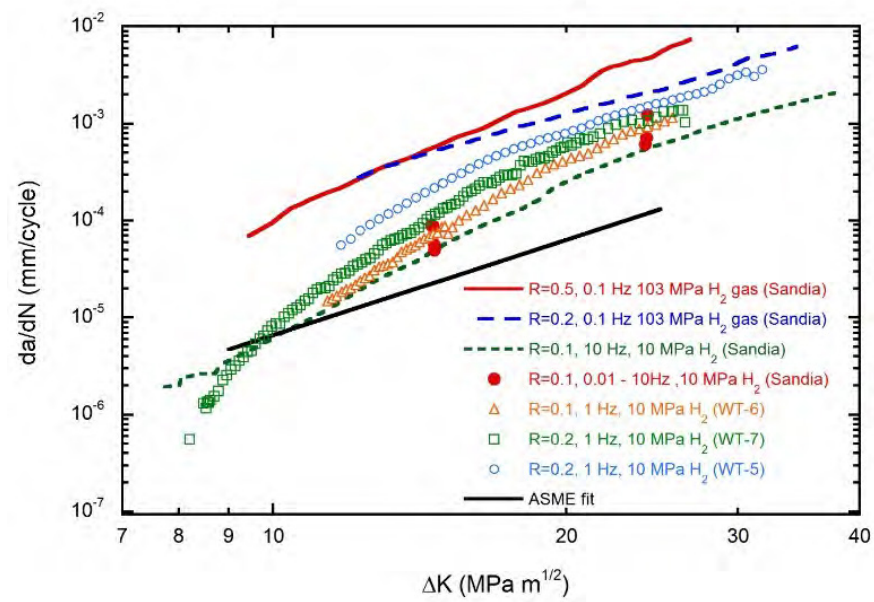

Fig. 3- Fatigue crack growth rates of the liner material in $\mathrm{H}_{2}$ environment at positive load ratios. The data referred to as Sandia data is from references $[11,12]$

Figure 5 shows a plot of FCGR for values of $\Delta \mathrm{K}$ of 10,20 , and $30 \mathrm{MPa} \sqrt{m}$ for $\mathrm{R}$ values of $-1.0,0.5,0.1$, 0.2 , and 0.5 . This plot confirms that the dependence of FCGR on $\mathrm{R}$ in high pressure $\mathrm{H}_{2}$ begins to accelerate at $\mathrm{R}$ $=0.2$. An unanswered question is whether for $R>0.5$, the FCGR continues to increase or if it saturates to a plateau level once $\mathrm{R}$ reaches 0.5 . Some recent work shows some effects of load ratio even when it increases from 0.5 to
$0.7[13]$. From applications point of view, this is a critical question that must be addressed in future studies. Also, as mentioned before, the data for $\mathrm{R} \leq 0.2$ was obtained at a $\mathrm{H}_{2}$ pressure of $10 \mathrm{MPa}$ from this study, and at $\mathrm{R}=0.5$, the test pressure was $103 \mathrm{MPa}[11,12]$. The $\mathrm{da} / \mathrm{dN}$ for $\mathrm{R}=0.5$ is higher than for lower load ratios but since it was at higher $\mathrm{H}_{2}$ pressure, we are unable to separate the effects of $\mathrm{R}$ from those due to pressure.

Figure 6 shows all the available data from our study for $1.0 \leq \mathrm{R} \leq 0.2$ to characterize scatter and produce trends for use in design. The figure also shows the 95\% confidence upper bound trend and the mean behavior from the data. The $\mathrm{R}=0.5$ and $\mathrm{R}=0.2$ trend from Sandia data at $103 \mathrm{MPa} \mathrm{H}_{2}$ pressure and the ASME trend in air are also included for comparison. The fatigue crack growth rate constants are given in an earlier publication [9]

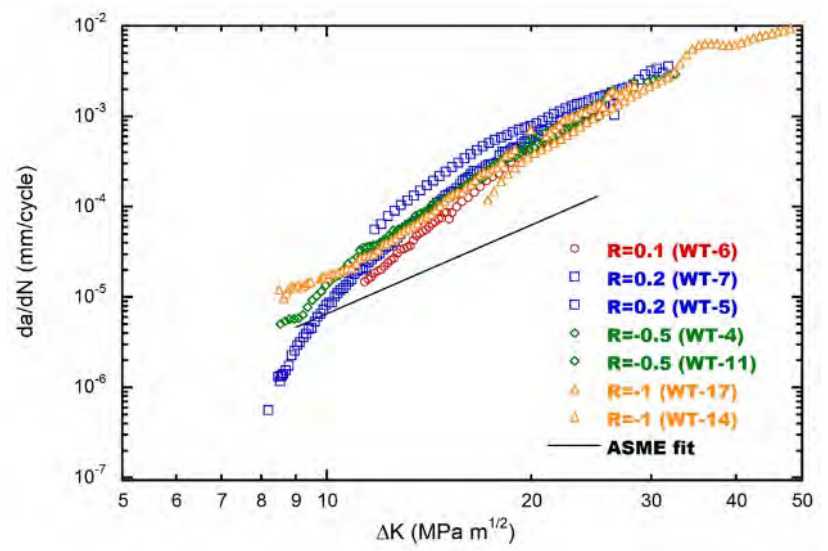

Fig. 4- Fatigue crack growth rate in the liner material for $-1.0 \leq$ $\mathrm{R} \leq 0.2$ in $10 \mathrm{MPa}$ hydrogen. The trend labelled ASME fit is for air environment.

\footnotetext{
* Corresponding author: asaxena@uark.edu
} 


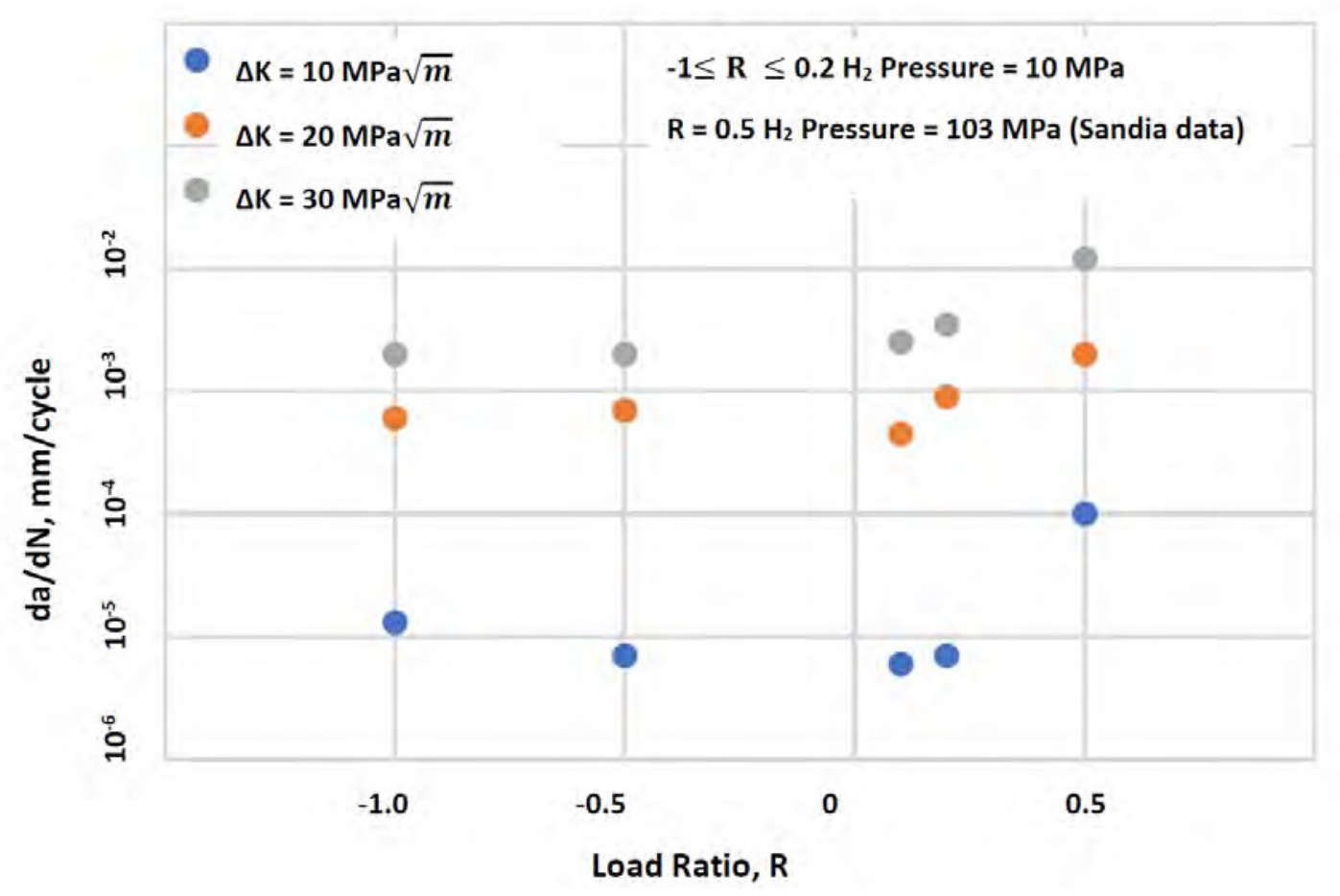

Fig. 5- FCGR behavior of A372 Grade L Class 70 as a function of load ratio R for three values of $\Delta K$

\subsection{Effects of Loading Frequency:}

The effects of loading frequency were investigated in previous studies on A372 Grade J Class 70 steels [12] in the range of 10 to $0.001 \mathrm{~Hz}$ at $\mathrm{R}=0.1$ and $\mathrm{H}_{2}$ pressures of 10,45 , and $103 \mathrm{MPa}$ for $\Delta \mathrm{K}$ levels of 15 and $24 \mathrm{MP} \sqrt{m}$. As the loading frequency decreased, the crack growth rates increased modestly. The largest increase in crack growth rates were observed when the loading frequency decreased from $10 \mathrm{~Hz}$ to $1 \mathrm{~Hz}$, by approximately a factor of 3 . Between $1 \mathrm{~Hz}$ and $0.001 \mathrm{~Hz}$, the increase in crack growth rates were small, especially in relation to random scatter in the data. Also, the effects of frequency appeared to be stronger at $\mathrm{H}_{2}$ pressure of 10 MPa than at 45 and $103 \mathrm{MPa}$. The results from our studies are shown in Fig.7. Fatigue crack growth rates at a $\mathrm{H}_{2}$ pressure of $10 \mathrm{MPa}$ in the range of $0.01 \leq v \leq 10 \mathrm{~Hz}$ at $\mathrm{R}$ $=0.1$ and $\mathrm{R}=-1.0$ are shown for four values of $\Delta \mathrm{K}$ that were nominally $30,25,15$, and $9 \mathrm{MPa} \sqrt{m}$. The actual $\Delta \mathrm{K}$ values varied from the nominal values and are noted on Fig. 7. These data clearly show only a small effect of frequencies ranging from $1 \mathrm{~Hz}$ to $0.01 \mathrm{~Hz}$ on the crack growth rates at all $\Delta \mathrm{K}$ levels. It is thus concluded that tests conducted at frequencies of $1 \mathrm{~Hz}$ or slower yield crack growth rates that realistically include the effects of $\mathrm{H}_{2}$ pressure on the FCGR behavior. This conclusion is of practical importance when choosing the loading conditions for generating design relevant data.

\subsection{Effects of Hydrogen Pressure on FCGR Behavior:}

The effect of $\mathrm{H}_{2}$ pressure on the fatigue crack growth behavior was investigated by Somerday et al. [11, 12] so their results are included here. It is well known that the effects of, load ratio, loading frequency, and pressure can be synergistic so it is impossible to totally isolate the effects of one variable from that of the others. However, it is possible to get some sense of the relative importance of these variables from experimental trends. Figure 8 shows the effect of varying $\mathrm{H}_{2}$ pressure on the FCGR behavior of A 372 Grade J, Class 70 steels in which the frequencies have been varied by 4 orders of magnitude. Varying frequency over 4 orders of magnitude produces a difference within a factor of 2 to 3 at most in crack growth rates as also reported in Fig.7. By comparison, increasing $\mathrm{H}_{2}$ pressure from $10 \mathrm{MPa}$ to $45 \mathrm{MPa}$ causes an increase in the FCGR by as much as by a factor of 4 . But, further increases in FCGR due to increases in pressure from 45 $\mathrm{MPa}$ to $100 \mathrm{MPa}$ were small. Note that the $100 \mathrm{MPa}$ crack growth data in Fig. 8 was for $\mathrm{R}=0.2$ compared to $\mathrm{R}=0.1$ condition for the other tests. Generation of additional data is necessary to document this trend.

Figure 9 shows the FCGR behavior of A372 Grade J Class 70 steel at $\Delta \mathrm{K}$ levels of 10,20 , and 25 $\mathrm{MPa} \sqrt{m}$ for various $\mathrm{H}_{2}$ pressures. The rates are presented as average actual rates and in a normalized form in which the actual rates are normalized by the rates in air at the corresponding $\Delta \mathrm{K}$ value. Differences in crack growth

\footnotetext{
* Corresponding author: asaxena@uark.edu
} 


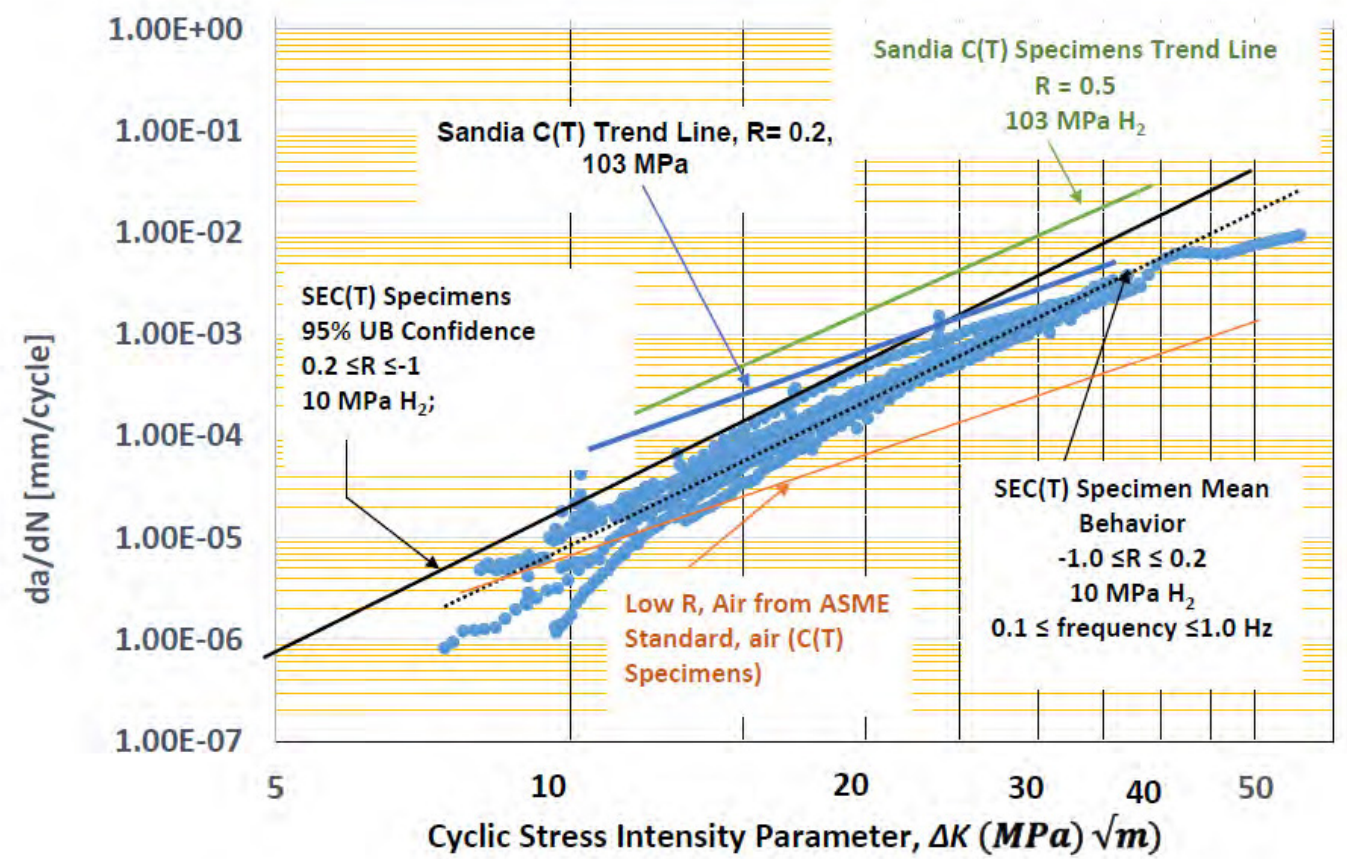

Fig. 6- All FCGR data produced as part of this study for $-1 \leq \mathrm{R} \leq 0.2$ on $10 \mathrm{MPa} \mathrm{H}_{2}$ using $\mathrm{SEC}(\mathrm{T})$ specimens and comparison with Sandia data from $\mathrm{C}(\mathrm{T})$ specimens at $\mathrm{H}_{2}$ pressure of $103 \mathrm{MPa}$ for $\mathrm{R}$ values of 0.5 and 0.2 [9].

rates due to pressure seem to be smaller for $\Delta \mathrm{K}$ values in the range of $10 \mathrm{MPa} \sqrt{m}$ than at higher $\Delta \mathrm{K}$ values of 20 and $25 \mathrm{MPa} \sqrt{m}$. More data at $\mathrm{H}_{2}$ pressure of $100 \mathrm{MPa}$ is needed to fully confirm this trend. Figure 9 also shows how the effects of increasing $\mathrm{H}_{2}$ pressure saturate beyond $45 \mathrm{MPa}$ at the various $\Delta \mathrm{K}$ levels. This should also be explored with more data in the future to confirm (or not) this trend.

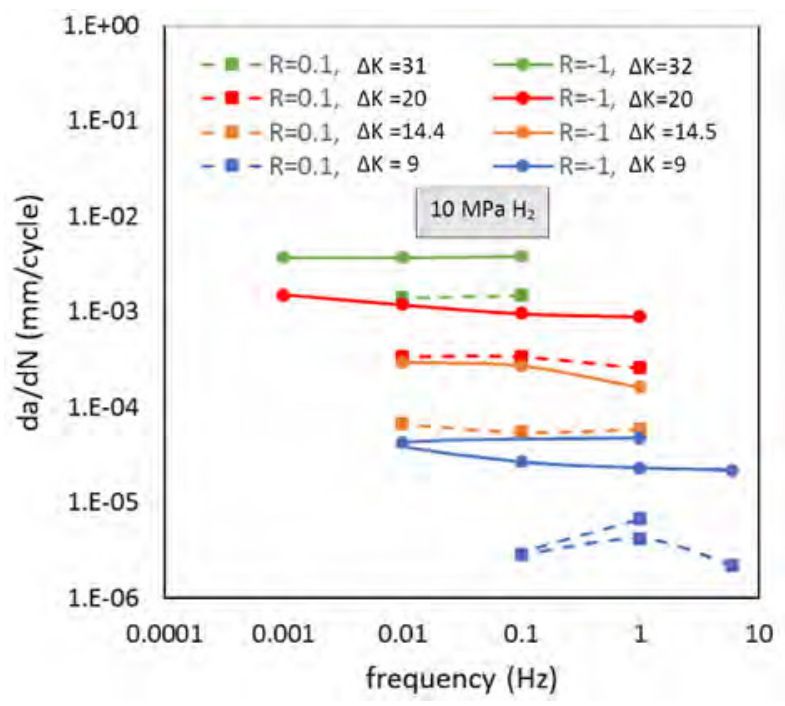

Fig. 7- Effect of loading frequency on the fatigue crack growth rates in $10 \mathrm{MPa} \mathrm{H} \mathrm{H}_{2}$ pressure at $\mathrm{R}=-1.0$ and at $\mathrm{R}=0.1$ at four $\Delta \mathrm{K}$ levels for A372 Grade J Class 70 steel [9].

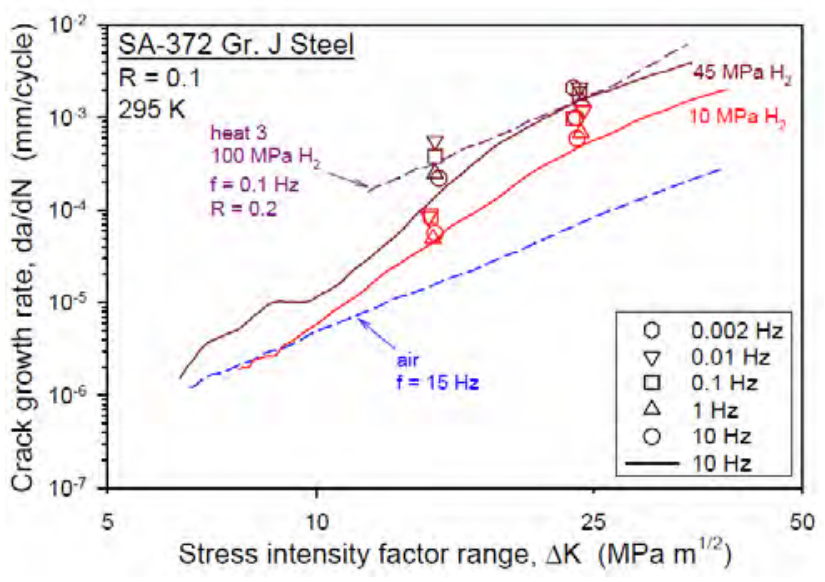

Fig. 8- FCGR behavior of A372 Grade J, Class 70 steel at various $\mathrm{H}_{2}$ pressures for $\mathrm{R}=0.1$. Reproduced from reference [17] with permission.

\section{Summary}

As mentioned previously, the effects of load ratio, loading frequency, and pressure are complex and synergistic in nature. However, a picture that appears to be evolving based on the evidence presented in this paper subject to additional experimental confirmation is as follows:

- $\quad$ FCGR behavior in high pressure $\mathrm{H}_{2}$ gaseous environment at negative load ratios of -1.0 and -0.5 are comparable to those at load ratios of 0.1 and 0.2 if the negative portion of the loading cycle is not included in the estimation of $\Delta \mathrm{K}$. This clearly underscores the benefits of the autofrettage process in enhancing the fatigue crack growth life of hydrogen storage vessels. The benefits

\footnotetext{
* Corresponding author: asaxena@uark.edu
} 


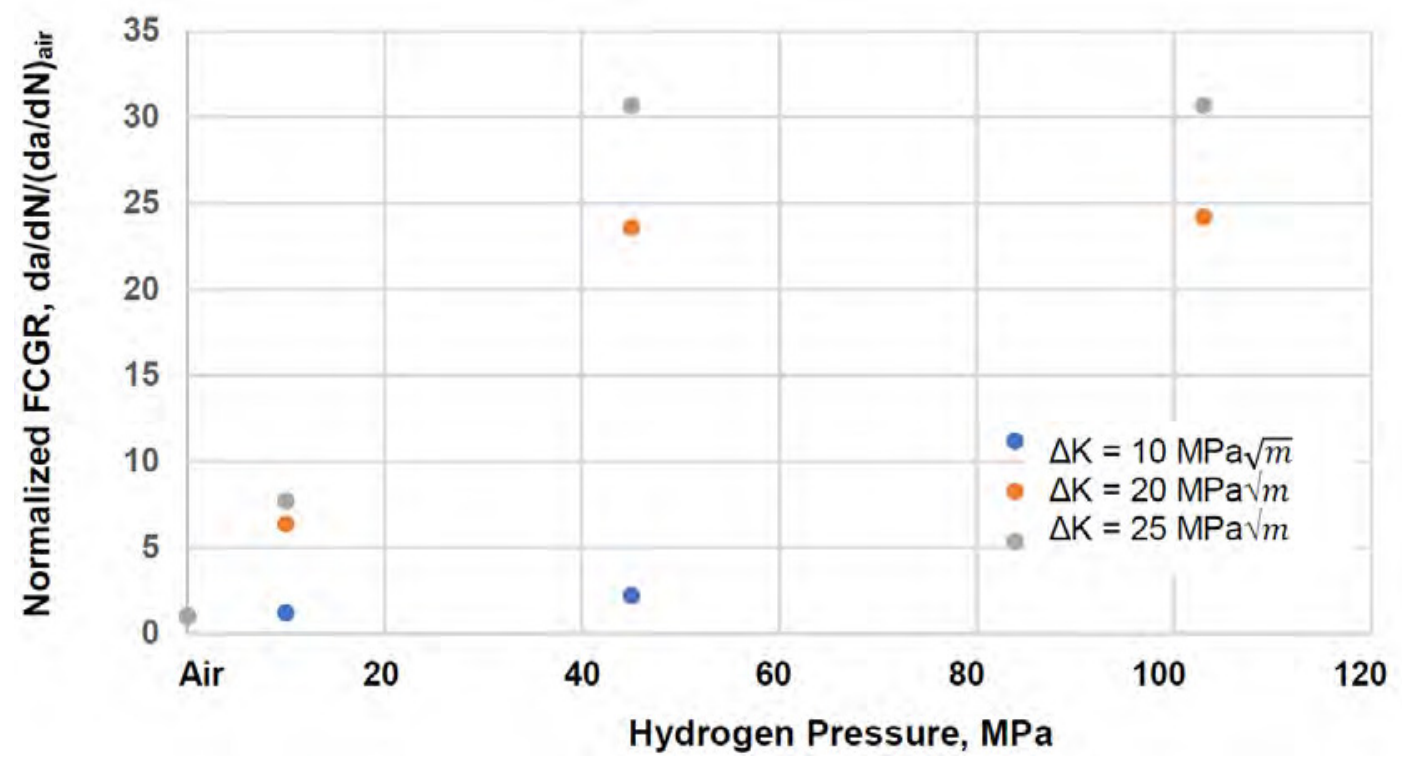

Fig. 9- FCGR behavior in $\mathrm{H}_{2}$ gas environment at various pressures normalized by the corresponding crack growth rates in air to highlight the extent of embrittlement [9]

accrue from a reduced $\Delta \mathrm{K}$ level as well as through a reduction in load ratio. The load ratio effects in high pressure gaseous $\mathrm{H}_{2}$ appear to become significant for $\mathrm{R}>$ 0.2 and especially in the pressure range of $100 \mathrm{MPa}$.

The loading frequency is a secondary variable in determining the crack growth rates in $\mathrm{H}_{2}$ environment and decreasing it does increase crack growth rates in the range of 10 to $1 \mathrm{~Hz}$ but it changes marginally when decreased beyond $1 \mathrm{~Hz}$. Thus, $0.1 \mathrm{~Hz} \leq v \leq 1 \mathrm{~Hz}$ is a suitable range for testing while producing data relevant for design of pressure vessels for storing $\mathrm{H}_{2}$.

The available data show that FCGR behavior in gaseous $\mathrm{H}_{2}$ do increase with increasing pressure. The magnitude of this effect appears to be highest in going from air environment to $10 \mathrm{MPa} \mathrm{H}_{2}$ pressure and appears to saturate at $45 \mathrm{MPa}$ level. Additional systematic studies to accurately quantify the effects of pressure are recommended.

\section{References}

1. A. Saxena, A. Prakash, K.A. Nibur, and I. Miller, "Considerations of the Effects of H2 in the Design of Type II Storage Vessels Built for Fatigue Resistance", Proceedings of the International Hydrogen Conference, B.P. Somerday and P. Sofronis editors, ASME-861387, 2017, pp 382-.389.

2. A. Prakash, G.R. Sharp, B.T. Deeken, W.J. Head, W.H. Thomson, "Steel Wrapped Pressure Vessel" US Patent US 9,266,642- B2 issued Feb. 2016.

3. ASME Section VIII, Division 3, Code 2004 Edition, "Alternate Rules for Construction of High Pressure Vessels”, ASME New York 10010.
4. M.D. Rana, G.B. Rawls, J.R. Sims, E. Upitis, , "Technical Basis and Application of New Rules on Fracture Control of High Pressure Hydrogen Vessel in ASME Section VIII Division 3, PVP 2007-2603, 2007, ASME PVP Conference, San Antonio, Texas.

5. R.P. Gangloff " $\mathrm{H}_{2}$-Enhanced Deformation and Fracture in the Crack Tip Plastic Zone", Proceedings of the International Hydrogen Conference, B.P. Somerday and P. Sofronis editors, ASME-861387, 2017, pp.1-35.

6. K.A. Nibur, and B.P. Somerday, "Fracture and Fatigue Test Methods in Hydrogen Gas" Gaseous Hydrogen Embrittlement of Materials in Energy Technologies, R.P. Gangloff and B.P. Somderday, eds., Woodhead Publishing Ltd., Cambridge, Vol. 1, 2012, pp.195-236.

7. B.P. Somerday, P. Bortot, and J. Felbaum, "Optimizing Measurement of Fatigue Crack Growth Relationships for Cr-Mo Pressure Vessel Steels in Hydrogen Gas", PVP2015-45424, Proc. ASME PVP Conference, July 19-23, 2015, Boston, MA.

8. K. A. Nibur, B.P. Somerday, C. San Marchi, J.W. Foulk, M. Dadfarina, P. Sofronis, "The Relationship Between Crack Tip Strain and Subcritical Cracking Thresholds in Steels in High Pressure Hydrogen Gas" Met. Transactions A, Vol. 44, 2013, pp248-269.

9. A. Saxena, K.A. Nibur, and A. Prakash, "Applications of Fracture Mechanics in Assessing Integrity of Hydrogen Storage Systems" Engineering Fracture Mechanics, 187, 2018, pp 368-380.

10. A. Saxena, F. Bassi, K.A. Nibur, and J.C. Newman, Jr., "On Single-Edge-Crack Specimen TensionCompression Fatigue Crack Growth Testing", Engineering Fracture Mechanics, 176, 2017, pp 343350.

\footnotetext{
* Corresponding author: asaxena@uark.edu
} 
11. B. P. Someday, P. Berlot, J. Felbaum, "Optimizing Measurement of Fatigue Crack Growth Relationships for Cr-Mo Pressure Vessel Steels in Hydrogen Gas", PVP-2015-45424, Proceedings of the ASME 2015 Pressure Vessel and the Piping Division Conference, July 19-23, 2015, Boston, MA

12. B.P. Somerday, C. San Marchi, and K. A. Nibur, "Measurement of Fatigue Crack Growth Rates in SA372 Grade J Steel in 100 MPA Hydrogen Gas Following Article KD-10, PVP 3013-97455, Proceedings of ASME 2013 Pressure Vessel and the Piping Division Conference, July 14-28, 2013, Paris, France.

13. San Marchi, C., Bortot, P., Felbaum, J., Wada, Y. and Ronevich, J.A. "Fatigue and Fracture of HighHardenability Steels for Thick-walled Hydrogen Pressure Vessels" Proceedings of the International Conference on hydrogen Safety, Sept 11-13, 2017, Hamburg Germany. 